\title{
Sex and Age Differences in Psychiatric Disorders among Children and Adolescents: High-Risk Students Study
}

\author{
Jae Hong Park, Young Rong Bang, and Chul Kwon Kim $\bowtie$ \\ Department of Psychiatry, Dong-A University College of Medicine, Busan, Republic of Korea
}

\begin{abstract}
Objective The aims of the present study are to investigate the rate of the psychiatric disorders in psychiatrically high-risk children and adolescents and to examine sex and age differences in the diagnosis of psychiatric disorders.

Methods The participants included students aged 6-16 from the 27 elementary and the 45 middle schools in Busan, Korea. We screened psychopathology using the Korean version of Child Behavior Checklist (K-CBCL) or the Youth Self Report (K-YSR). A total of 2,912 students were selected as high-risk students on the basis of cut-off scores (T-score $\geq 60$ ) for a total behavior problem score of K$\mathrm{CBCL} / \mathrm{K}-\mathrm{YSR}$. Of these high-risk students, 1,985 students participated in and completed individual diagnostic interviews. Psychiatric diagnosis was assessed using a Korean version of the Kiddie-Schedule for Affective Disorders and Schizophrenia. Multivariate logistic regression analysis was conducted to examine sex and age differences of psychiatric diagnosis.

Results Based on sex, boys were more likely to have ADHD and girls were more likely to have depression. Based on age, children were more likely to have ADHD and adolescents were more likely to have affective disorder, conduct disorder, psychotic disorder, and anxiety disorders except separation anxiety disorder.

Conclusion This is the largest study to conduct face-to-face interviews with subjects and parent(s) among Korean studies in this field. The present study revealed significant differences across sex and age among specific psychiatric disorders in children and adolescents. Future population-based studies will be required to ascertain the sex- and age-related differences of psychiatric prevalence.
\end{abstract}

Psychiatry Investig 2014;11(3):251-257

Key Words Psychiatric diagnosis, Sex, Age, Child, Adolescent, Epidemiology.

\section{INTRODUCTION}

Many adult psychiatric disorders have their onset during childhood and adolescence. In the United States, the National Institute of Mental Health Catchment Area Program demonstrated that the peak hazard rate for several psychiatric disorders was in childhood or adolescence. ${ }^{1}$ The National Comorbidity Survey-Replication study also confirmed this finding. ${ }^{2}$ Epidemiological findings show that a mean prevalence estimate of child and adolescent psychiatric disorder is $12 \%$ although estimates from international studies differ widely. ${ }^{3}$ Psychiatric disorders during childhood and adolescence are often a great burden to the individual's function and social

Received: July 30, 2013 Revised: September 25, 2013 Accepted: September 25, 2013 Available online: July 21, 2014

$\triangle$ Correspondence: Chul Kwon Kim, MD, PhD

Department of Psychiatry, Dong-A University College of Medicine, 26 Daesingonwon-ro, Seo-gu, Busan 602-715, Republic of Korea

Tel: +82-51-240-2908, Fax: +82-51-253-3542, E-mail: kimck@dau.ac.kr

(a) This is an Open Access article distributed under the terms of the Creative Commons Attribution Non-Commercial License (http://creativecommons.org/licenses/bync/3.0) which permits unrestricted non-commercial use, distribution, and reproduction in any medium, provided the original work is properly cited. relationships in the family and with friends. ${ }^{4}$ Thus, early recognition of child and adolescent psychiatric disorders may provide an opportunity to reduce lifelong consequences and promote individual capacity.

Developmentally, children and adolescents show sex- and age-based developmental differences of psychopathology. ${ }^{5}$ Epidemiological and clinical studies indicate sex and age differences in the rate of psychiatric disorders among children and adolescents. ${ }^{3,5}$ Psychiatric disorders in children and adolescents show different symptoms and severity according to their developmental stage. A number of biological, psychological, and social factors have been proposed to account for these differences. ${ }^{5}$ Understanding the sex and age differences in the rates of psychiatric disorders among children and adolescents is an essential component in understanding development of psychiatric disorders. ${ }^{6}$ Although these issues have been addressed by large epidemiological studies from a number of countries, no systematic study has been conducted in Korea. It is necessary to investigate the overall rates of major psychiatric disorders in Korean students and compare the results with 
those of Western countries in the context of cultural influence.

The objectives of this study were to examine the following: 1) the rate of the psychiatric disorders in psychiatrically highrisk children and adolescents and 2) sex and age differences in the diagnosis of psychiatric disorders. We hypothesized that Korean students would show sex- and age-differences in occurrence of psychiatric disorder.

\section{METHODS}

This study is part of the Mental Health Screening Project (MHSP) in Busan, Korea. The MHSP is a cross-sectional and school-based screening survey whose aims are to screen mental health problems among school students (grades 1st-9th) and provide clinical services for high-risk students. The study was designed with two stages: first, a screening stage using a self-report instrument; second, an individual psychiatric interview stage using a structured diagnostic instrument. Informed consent to participate in this study was provided by participants/parents. Ethical approval for the study was obtained from the Institutional Review Board of Dong-A University Hospital. The study was conducted between May 2011 and February 2012.

\section{Measures}

\section{Screening instruments}

In the initial screening stage, all participants were administered a self-report questionnaire. We used a Korean version of the Child Behavior Checklist (K-CBCL) for elementary school students (grades 1st-6th) and the Youth Self-Report (K-YSR) for middle school students (grades 7th-9th) as screening instruments in the first stage. Although they target different age groups, K-CBCL and K-YSR yield the same syndrome scores for the same emotional and behavioral problems. K-CBCL and K-YSR have been widely used and have shown high reliability and validity when used as screening tests for mental health problems of children and adolescents. Scores from K-CBCL/K-YSR are computed as T-scores. T score $\geq 60$ indicate subclinical significance and $\geq 65$ indicate clinical significance. ${ }^{7}$ In this study, students with a 60 T-score or above for their total problem score, which is the leading score of $\mathrm{K}$ CBCL/K-YSR, were selected for psychiatrically high-risk students and thus candidates for the individual interview stage.

\section{Diagnostic instrument}

In the individual interview stage, we assessed psychiatric disorders using a Korean version of the Kiddie-Schedule for Affective Disorders and Schizophrenia-Present and Lifetime Version (K-SADS-PL-K). The K-SADS-PL-K has good reli- ability and validity when diagnosing psychiatric disorders in children and adolescents. ${ }^{8}$ The disorders assessed in this study included three subtypes of attention-deficit hyperactivity disorder (ADHD) (inattentive type, hyperactive type, combined type), conduct disorder, three affective disorders (depression, dysthymic disorder, bipolar disorder), seven anxiety disorders [separation anxiety disorder (SAD), specific phobia, social phobia, agoraphobia, generalized anxiety disorder (GAD), obsessive compulsive disorder (OCD), post-traumatic stress disorder (PTSD)], and psychotic disorder. The K-SADS-PL-K was administered by four professional psychiatrists, six psychiatry residents, and six clinical psychologists who were blinded to each participant's scores on the K-CBCL/K-YSR. After two training sessions and three case rehearsals, inter-rater agreement for psychiatric diagnosis was substantial $(\kappa=0.75)$.

\section{Demographic variables}

The demographic variables evaluated were sex, age, economic status, and family structure. All of demographic variables were collected by the self-reported method.

\section{Participants and procedure}

The participants included students aged 6-16 from the 27 elementary and the 45 middle schools in Busan, Korea. Students from special education schools were not included in the present study. Informed consent was attained from 43,621 students. In the initial screening stage, a total of 34,758 students fully completed the survey questionnaire. The overall response rate was $79.7 \%$ in the screening stage. Among them, a total of 2,912 students $(8.4 \%)$ were selected as high-risk students on the basis of cut-off scores (T-score $\geq 60$ ) for a total behavior problem score of K-CBCL/K-YSR. Of these high-risk students, 1,985 students (68.2\%) participated in and completed individual diagnostic interviews and were left in the final analysis. Information was obtained from subjects and their parent(s) during the interview session. Students who did not participate in the diagnostic interview $(n=927,31.8 \%)$ were not significantly different with regard to age $(\mathrm{t}=1.65, \mathrm{p}=0.10)$, $\operatorname{sex}\left(\chi^{2}=0.01, p=0.94\right)$, economic status $\left(\chi^{2}=4.01, p=0.14\right)$, and total behavioral problem scores of K-CBCL/K-YSR ( $\mathrm{t}=0.01$, $\mathrm{p}=0.99$ ) as compared to those who participated.

\section{Statistical analysis}

We analyzed data from 1,985 students who completed the diagnostic interview. Descriptive statistics were used to present demographic variables and the frequency of psychiatric diagnosis. To ascertain the differences by sex and age, a series of analyses were conducted. We dichotomized age groups based on the level of development: children (6-12 years old) and adolescents (13-16 years old). Next, we performed mul- 
tivariate logistic regression analysis including demographic characteristics as independent variables and each psychiatric diagnosis as dependent variables. The first model, which included sex and age groups separately as a sole independent variable, was used to calculate the unadjusted odds ratio (OR) for boys (vs. girls) and for adolescents (vs. children). In the second model, sex and age groups were mutually adjusted and the interaction term between sex and age groups was added. The final model was adjusted for other associated sociodemographic variables. All variables were entered simultaneously. The significance level was set at $\mathrm{p}<0.05$. All analyses were conducted using the SPSS 12.0 (version 12.0, SPSS Inc., Chicago, IL, USA).

\section{RESULTS}

\section{Demographic variables and overall psychiatric disorders of the study sample}

Of the psychiatrically high-risk students $(n=1,985), 50.5 \%$ were boys and $49.5 \%$ were girls. The mean age was 12.02 years $(\mathrm{SD}=2.3)$. Of these, $933(47.0 \%)$ subjects were classified as children (aged 6-12) and 1,052 (53.0\%) as adolescents (aged 13-16). Most subjects lived in two-parent households (76.1\%) and were of low to middle economic status (90.8\%, Table 1).

A total of 1,335 subjects (67.3\%) had at least one psychiatric disorder. The most frequent psychiatric disorders were $\mathrm{AD}$ HD (36.7\%), depression (28.4\%), and anxiety disorder (17.7\%), followed by conduct disorder (5.3\%), dysthymia (4.6\%), psychotic disorder (2.4\%), and bipolar disorder (0.8\%, Table 2).

Table 1. Demographic characteristics of the study subject $(\mathrm{N}=$ 1985)

\begin{tabular}{lcc}
\hline \multicolumn{1}{c}{ Demographic characteristics } & $\mathrm{N}$ & $\%$ \\
\hline Sex & 1003 & 50.5 \\
Boys & 982 & 49.5 \\
$\quad$ Girls & 12.02 (mean) & $2.3(\mathrm{SD})$ \\
Age (year) & & \\
Age group & 933 & 47.0 \\
$\quad$ Children (6-12 years) & 1052 & 53.0 \\
Adolescent (13-16 years) & & \\
Family structure & 1511 & 76.1 \\
$\quad$ Live with both parents & 357 & 18.0 \\
Live with one parent & 75 & 3.8 \\
Live with grandparents only & 42 & 2.1 \\
Live apart from parents & & \\
Economic status & 182 & 9.2 \\
High & 819 & 41.2 \\
Middle & 984 & 49.6 \\
Low & &
\end{tabular}

\section{Differences of psychiatric disorders by sex}

Compared to girls, boys were more likely to have ADHD $(\mathrm{OR}=2.14,95 \%$ CI: 1.77-2.59, $\mathrm{p}<0.001)$. Among ADHD subtypes, rate of $\mathrm{ADHD}$ combined type was significantly higher in boys (OR=2.47, 95\% CI: 1.97-3.1, p<0.001). Rates of AD$\mathrm{HD}$ inattentive type and hyperactive type were similar for both sexes.

Boys were protective against depression $(\mathrm{OR}=0.64,95 \%$ CI: 0.52-0.78, $\mathrm{p}<0.001$ ), indicating higher rates among girls than boys. Although overall affective disorder OR was lower in boys (OR=0.63, 95\% CI: 0.52-0.76, p<0.001), the OR of dysthymia and bipolar disorder were similar for both sexes. Boys and girls had similar rates of conduct disorder, anxiety disorder, and psychosis (Table 3, Figure 1).

\section{Differences of psychiatric disorders by age}

Compared to children, adolescents had a significantly lower OR of ADHD (OR=0.67, 95\% CI: 0.55-0.80, p<0.001), indi-

Table 2. Diagnostic characteristics of the study subjects

\begin{tabular}{|c|c|c|c|}
\hline Psychiatric disorders & $\mathrm{N}$ & $\% *$ & $\%^{\dagger}$ \\
\hline \multicolumn{4}{|l|}{$\mathrm{ADHD}$} \\
\hline Overall & 728 & 36.7 & 25.0 \\
\hline Inattentive & 209 & 10.5 & 7.2 \\
\hline Hyperactive & 67 & 3.4 & 2.3 \\
\hline Combined & 452 & 22.8 & 15.5 \\
\hline \multicolumn{4}{|l|}{ Conduct disorder } \\
\hline Overall & 106 & 5.3 & 3.6 \\
\hline \multicolumn{4}{|l|}{ Affective disorder } \\
\hline Overall & 642 & 32.3 & 22.0 \\
\hline Depression & 563 & 28.4 & 19.3 \\
\hline Dysthymia & 91 & 4.6 & 3.1 \\
\hline Bipolar disorder & 16 & 0.8 & 0.5 \\
\hline \multicolumn{4}{|l|}{ Anxiety disorder } \\
\hline Overall & 352 & 17.7 & 12.1 \\
\hline SAD & 34 & 1.7 & 1.2 \\
\hline Specific phobia & 90 & 4.5 & 3.1 \\
\hline Social phobia & 45 & 2.3 & 1.5 \\
\hline Agoraphobia & 17 & 0.9 & 0.6 \\
\hline GAD & 141 & 7.1 & 4.8 \\
\hline OCD & 15 & 0.8 & 0.5 \\
\hline PTSD & 65 & 3.3 & 2.2 \\
\hline Psychotic disorder & 47 & 2.4 & 1.6 \\
\hline Any disorder & 1335 & 67.3 & 45.8 \\
\hline
\end{tabular}

*percentages of interview participants $(\mathrm{N}=1985),{ }^{\dagger}$ percentages of total screened sample ( $\mathrm{N}=2912)$. ADHD: attention deficit hyperactivity disorder, SAD: separation anxiety disorder, GAD: generalized anxiety disorder, OCD: obsessive compulsive disorder, PTSD: posttraumatic stress disorder 
Table 3. Sex-based difference of psychiatric disorders

\begin{tabular}{|c|c|c|c|c|c|c|}
\hline & & Girls (N=982) & Boys $(\mathrm{N}=1003)$ & OD+ & $050<C \mathrm{I}$ & \\
\hline & & $\mathrm{N}(\%)$ & $\mathrm{N}(\%)$ & Uत & (35\% & $\mathrm{p}$ \\
\hline \multirow[t]{4}{*}{ ADHD } & Overall & $271(27.6)$ & $457(45.6)$ & 2.14 & $1.77-2.59$ & $<0.001$ \\
\hline & Inattentive & $102(10.4)$ & $107(10.7)$ & 1.06 & $1.06-0.79$ & - \\
\hline & Hyperactive & $26(2.6)$ & $41(4.1)$ & 1.41 & $0.84-2.37$ & - \\
\hline & Combined & $143(14.6)$ & $309(30.8)$ & 2.47 & $1.97-3.1$ & $<0.001$ \\
\hline Conduct disorder & & $52(5.3)$ & $54(5.4)$ & 1.73 & $0.96-3.14$ & - \\
\hline \multirow[t]{4}{*}{ Affective disorder } & Overall & $374(38.1)$ & $268(26.7)$ & 0.63 & $0.52-0.76$ & $<0.001$ \\
\hline & Depression & $327(33.3)$ & $236(23.5)$ & 0.64 & $0.52-0.78$ & $<0.001$ \\
\hline & Dysthymia & $52(5.3)$ & $39(3.9)$ & 0.87 & $0.51-1.47$ & - \\
\hline & Bipolar disorder & $12(1.2)$ & $4(0.4)$ & 0.35 & $0.11-1.10$ & - \\
\hline \multirow[t]{8}{*}{ Anxiety disorder } & Overall & $179(18.2)$ & $173(17.2)$ & 0.97 & $0.76-1.0$ & - \\
\hline & SAD & $19(1.9)$ & $15(1.5)$ & 0.81 & $0.39-1.71$ & - \\
\hline & Specific phobia & $39(4.0)$ & $51(5.1)$ & 1.34 & $0.86-2.11$ & - \\
\hline & Social phobia & $16(0.8)$ & $29(2.9)$ & 1.64 & $0.85-3.16$ & - \\
\hline & Agoraphobia & $9(0.9)$ & $8(0.8)$ & 0.9 & $0.29-2.76$ & - \\
\hline & GAD & $76(7.7)$ & $65(6.5)$ & 0.85 & $0.59-1.22$ & - \\
\hline & OCD & $5(0.5)$ & $10(1.0)$ & 1.94 & $0.65-5.83$ & - \\
\hline & PTSD & $38(3.9)$ & $27(32.8)$ & 0.81 & $0.46-1.41$ & - \\
\hline Psychotic disorder & & $28(2.9)$ & $19(1.9)$ & 0.82 & $0.39-1.72$ & - \\
\hline Any disorder & & $627(63.8)$ & $708(70.6)$ & 1.41 & $1.16-1.70$ & $<0.001$ \\
\hline
\end{tabular}

*reference group=girls, ${ }^{\dagger}$ adjusted for sex, age, interaction term of sex and age, family structure, and economic status. ADHD: attention deficit hyperactivity disorder, SAD: separation anxiety disorder, GAD: generalized anxiety disorder, OCD: obsessive compulsive disorder, PTSD: posttraumatic stress disorder

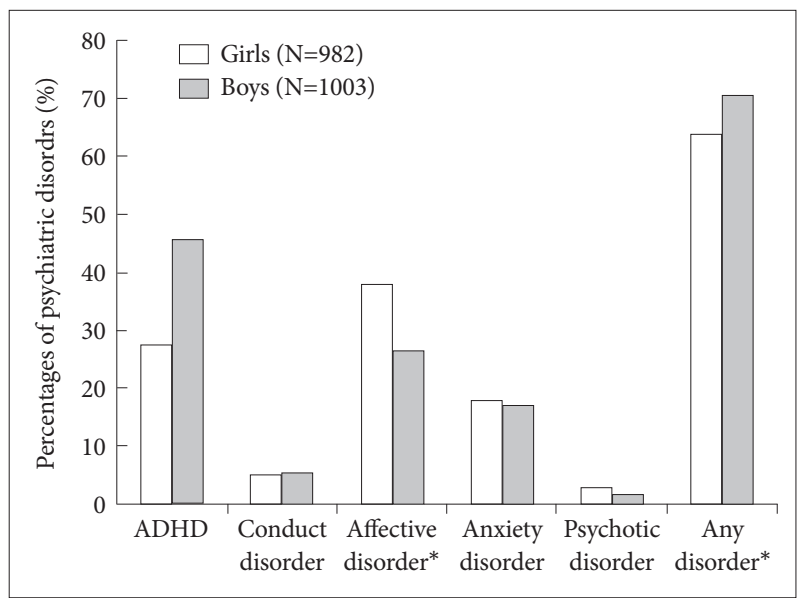

Figure 1. Sex-based diffrences of psychiatric disorders. ${ }^{*} p<0.001$. ADHD: attention deficit hyperactivity disorder.

cating higher rate among children than adolescents. Among ADHD subtypes, OR of ADHD hyperactive type (OR=0.57, 95\% CI: $0.35-0.95, \mathrm{p}=0.03)$ and combined type (OR=0.58, $95 \%$ CI: $0.47-0.72, \mathrm{p}<0.001)$ were lower in adolescents than children. Rates of ADHD inattentive type were similar for both age groups. Adolescents had a significantly higher OR of conduct disorder than children (OR=4.13, 95\% CI: 2.51-6.78, $\mathrm{p}<0.001)$.

Adolescents were more likely to have an overall affective disorder ( $\mathrm{OR}=2.09,95 \%$ CI: 1.72-2.55, $\mathrm{p}<0.001)$, depression $(\mathrm{OR}=1.68,95 \% \mathrm{CI}: 1.37-2.06, \mathrm{p}<0.001)$, and dysthymia $(\mathrm{OR}=$ $3.66,95 \%$ CI: $2.16-6.21, \mathrm{p}<0.001)$. The rate of bipolar disorder did not show any age difference.

Adolescents had a higher rate of overall anxiety disorder (OR=1.72, 95\% CI: 1.36-2.19, $\mathrm{p}<0.001)$. More specifically, adolescents were more likely to have a specific phobia ( $\mathrm{OR}=1.79$, 95\% CI: $1.14-2.79, \mathrm{p}=0.01)$, social phobia ( $\mathrm{OR}=2.13,95 \%$ CI: 1.12-4.04, $\mathrm{p}=0.02)$, GAD (OR=1.76, 95\% CI: $1.23-2.53$, $\mathrm{p}=0.002)$, and PTSD (OR=2.26, 95\% CI: 1.30-3.93, $\mathrm{p}=0.004)$. However, the OR of SAD (OR=0.35, 95\% CI: $0.17-0.74, \mathrm{p}=$ 0.006 ) was significantly lower in adolescents than children, indicating higher rates among children than adolescents. Adolescents also had a higher rate of psychotic disorder $(\mathrm{OR}=$ 3.73, 95\% CI: 1.79-7.78, p<0.001) than children (Table 4, Figure 2).

\section{DISCUSSION}

To our knowledge, this is the largest study involving faceto-face interviews with subjects and parents ever conducted 
Table 4. Age-based difference of psychiatric disorders

\begin{tabular}{|c|c|c|c|c|c|c|}
\hline & & Children (N=933) & Adolescents $(\mathrm{N}=1052)$ & & & \\
\hline & & N (\%) & N (\%) & Uत & 1980 & $P$ \\
\hline \multirow[t]{4}{*}{ ADHD } & Overall & $396(42.4)$ & $332(31.6)$ & 0.67 & $0.55-0.80$ & $<0.001$ \\
\hline & Inattentive & $89(9.5)$ & $120(11.4)$ & 1.23 & $0.92-1.64$ & - \\
\hline & Hyperactive & $41(4.4)$ & $26(2.5)$ & 0.57 & $0.35-0.95$ & 0.03 \\
\hline & Combined & $266(28.5)$ & $186(17.7)$ & 0.58 & $0.47-0.72$ & $<0.001$ \\
\hline Conduct disorder & & $20(2.1)$ & $86(8.2)$ & 4.13 & $2.51-6.78$ & $<0.001$ \\
\hline \multirow[t]{4}{*}{ Affective disorder } & Overall & $220(23.6)$ & $422(40.1)$ & 2.09 & $1.72-2.55$ & $<0.001$ \\
\hline & Depression & $209(22.4)$ & $354(33.7)$ & 1.68 & $1.37-2.06$ & $<0.001$ \\
\hline & Dysthymia & $18(1.9)$ & $73(6.9)$ & 3.66 & $2.16-6.21$ & $<0.001$ \\
\hline & Bipolar disorder & $4(0.4)$ & $12(1.1)$ & 2.43 & $0.78-7.59$ & - \\
\hline \multirow[t]{8}{*}{ Anxiety disorder } & Overall & $127(13.6)$ & $225(21.4)$ & 1.72 & $1.36-2.19$ & $<0.001$ \\
\hline & SAD & $24(2.9)$ & $10(1.0)$ & 0.35 & $0.17-0.74$ & 0.006 \\
\hline & Specific phobia & $31(3.3)$ & $59(5.6)$ & 1.79 & $1.14-2.79$ & 0.01 \\
\hline & Social phobia & $14(2.9)$ & $31(9.0)$ & 2.13 & $1.12-4.04$ & 0.02 \\
\hline & Agoraphobia & $4(0.4)$ & $13(1.2)$ & 2.89 & $0.94-8.94$ & - \\
\hline & GAD & $48(5.1)$ & $93(8.8)$ & 1.76 & $1.23-2.53$ & 0.002 \\
\hline & OCD & $6(0.6)$ & $9(0.9)$ & 1.43 & $0.50-4.05$ & - \\
\hline & PTSD & $18(1.9)$ & $47(4.5)$ & 2.26 & $1.30-3.93$ & 0.004 \\
\hline Psychotic disorder & & $9(1.0)$ & $38(3.6)$ & 3.73 & $1.79-7.78$ & $<0.001$ \\
\hline Any disorder & & $599(64.2)$ & $736(70.0)$ & 1.33 & $1.10-1.61$ & 0.003 \\
\hline
\end{tabular}

*reference group=children, ${ }^{t}$ adjusted for sex, age, interaction term of sex and age, family structure, and economic status. ADHD: attention deficit hyperactivity disorder, SAD: separation anxiety disorder, GAD: generalized anxiety disorder, OCD: obsessive compulsive disorder, PTSD: posttraumatic stress disorder

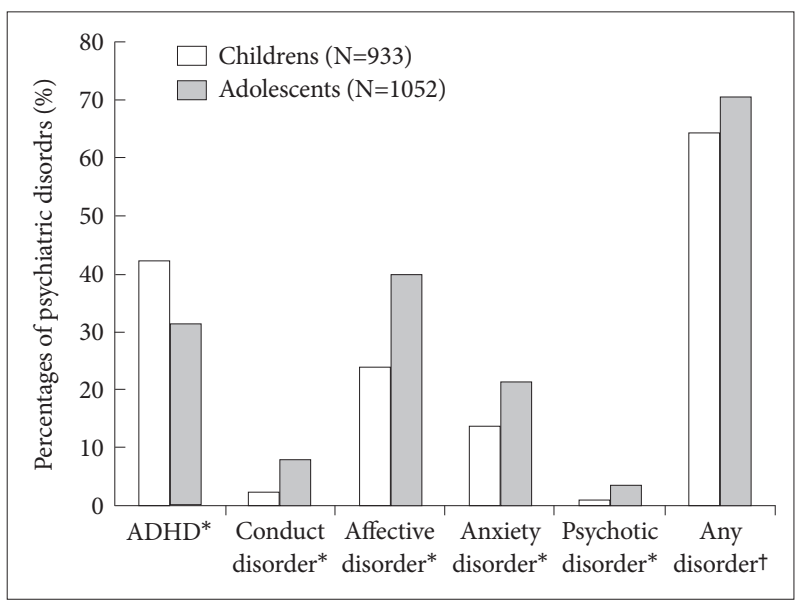

Figure 2. Age-based diffrences of psychiatric disorders. ${ }^{*} \mathrm{p}<0.001$, $t p=0.003$. ADHD: attention deficit hyperactivity disorder.

in this field in Korea. A total of 1,985 subjects were evaluated with structured diagnostic interviews. This method may improve the diagnostic validity of the present results.

The present study revealed significant differences across sex and age among specific psychiatric disorders in children and adolescents. The rate of ADHD is higher in boys than girls, which is consistent with previous studies. ${ }^{9,10}$ This sex dif- ference might be affected by a difference within the ADHD combined type which is the most prevalent subtype of ADHD. In contrast to findings by Western researchers, ${ }^{11}$ the hyperactive/impulsive type of ADHD did not show a sex difference in our results. We postulate that cultural variation in the interpretation of children's hyperactivity may be at play here. In our clinical practice, we have noted that Korean parents see hyperactivity in girls as problematic and the same in boys as normal or even healthy. Informants' ratings of symptoms could be influenced by cultural attitude to hyperactivity. There is this possibility that girls with hyperactivity were more likely to be referred than boys with hyperactivity in the screening and interview stages. As a result, referral bias may have offset any sex difference in the rate of the hyperactive/impulsive type. Based on age, the adolescent group shows a lower rate of overall ADHD than the child group. Specifically, the rate of ADHD hyperactive/impulsive type shows a decline in adolescence, but the rate of ADHD inattentive type does not. This age dependent change of ADHD symptoms has been reported in other previous studies. ${ }^{12,13}$

The rate of conduct disorder did not show any sex difference in the present study. It has been generally accepted that boys usually exhibit a higher rate of conduct disorder. However, 
some studies have been reported in which boys do not always have a higher risk for conduct disorder than girls. ${ }^{14-16}$ These studies raise questions about the sex difference of conduct disorder. Our findings would thus need corroboration by further epidemiological and clinical studies.

In our study, depressive disorder shows female and adolescent predominance. It has been well-known that depression has an upsurge with the onset of puberty. ${ }^{17}$ Biological and psychosocial factors may interact to produce an increased rate of depression in adolescent girls. ${ }^{18}$ Female hormonal changes at puberty can be thought of as a risk factor for depression. ${ }^{19}$ Girls are more likely to experience negative events in the family than boys, and these adversities are in turn associated with elevated depression. ${ }^{20}$ From our preliminary analysis, students who live with one parent $(\mathrm{OR}=1.53, \mathrm{p}<0.05)$ or who live with grandparents only $(\mathrm{OR}=1.87, \mathrm{p}<0.05)$ are more likely to have depression. Although this result cannot fully explain the association between family adversity and depression, our results infer that family adversity is associated with the onset of depression.

The rate of bipolar disorder is too small to draw a conclusion in this study. Some diagnostic considerations are addressed in our result. First, for a diagnosis of bipolar disorder, it is necessary to meet the manic episode criteria in DSM-IV. However, in previous community studies, the occurrence of a depressive episode is usually the first manifestation of bipolar disorder. ${ }^{21}$ Thus, students with depression in our study can develop a bipolar disorder in their future. Second, given the overlap between symptoms of mania and ADHD, some children with bipolar symptoms are misdiagnosed as ADHD. Further longitudinal study will clarify this diagnostic ambiguity.

The present study shows no remarkable sex differences in rates of anxiety disorders. This result is consistent with previous clinical sample studies which reported equal sex rates of anxiety disorders in boys and girls. ${ }^{22,23}$ The sample of our study is a clinically high-risk group, which is similar to a clinical sample. However, general population studies report female predominance in anxiety disorders. ${ }^{24-26}$ It is postulated that sex differences in the prevalence of anxiety disorders differ between general population samples and the clinical sample. Another possible explanation of this result would be that underdiagnosed boys with anxiety disorder may have been picked up in our study. Because anxiety is part of normal development, it may be difficult for a layperson to distinguishing normal and pathological anxiety. Diagnostic interviews conducted by mental health professionals in our study could strengthen the ability to detect underdiagnosed children with anxiety disorder. Based on age, the results of the present study correspond with previous studies which reported that overall anxiety disorders were diagnosed more often in adolescents than children with the exception of SAD. ${ }^{27,28}$ This result reaffirms the previous finding that $\mathrm{SAD}$ is a predominantly childhood condition. ${ }^{29}$

The present study requires interpretation within the context of several limitations. First, findings of the present study are limited by sample selection. In our results, the rates of psychiatric diagnosis cannot represent prevalence, because the sample was neither randomly selected nor population-based. Nearly half of our sample responded that they have low economic status. Because low economic status is an important risk factor for psychiatric disorders, it may have influenced the present results. Moreover, the present study included psychiatrically high-risk subjects, which results in the high percentages of psychiatric diagnosis. In our study, students from special education schools were not included in study population. Students from special education schools have more severe developmental disabilities, such as severe mental retardation and autism with severe behavioral problems. Our results thus do not reflect psychopathology among those students. Referral bias should also be considered when interpreting our findings. However, our findings provide valuable information about rates of psychiatric diagnosis in mental health screening studies and clinical settings. Second, we were unable to include high school students (grades 10th-12th) in the sample. This means that late adolescence data on mental disorders are not available in the present study. Third, information was obtained from students and parent(s). We could not obtain data from teachers who could have provided information on behavioral and emotional impairment in the school context. Fourth, we could not include all the DSM-IV diagnosis. We would have preferred to focus on the most frequent and functionally impairing psychiatric diagnosis among children and adolescents. Fifth, screening criteria used in this study need further validation. Although K-CBCL and K-YSR have been shown to have good reliability and validity in several studies which investigated specific psychopathology (e.g., ADHD, ${ }^{30}$ depression, ${ }^{31}$ anxiety, ${ }^{32}$ etc.), their validity for epidemiological studies has yet to be established.

In summary, this study demonstrates sex and age differences of psychiatric diagnosis among children and adolescents. Findings of our study would provide basic data that would be useful for studying causal mechanisms of psychopathology. The present study calls for future population-based studies on sex- and age-related differences of psychiatric prevalence. Our study also adds to the information on public mental health intervention. First, this study supports the necessity of school-based mental health screening to better focus on early intervention. Second, we suggest prioritizing the allocation of mental health service resources by identifying the most prev- 
alent psychiatric disorders in general (e.g., ADHD, depression) and by sex and age.

\section{Acknowledgments}

This work was supported by the Dong-A University research fund.

\section{REFERENCES}

1. Burke KC, Burke JD, Jr, Regier DA, Rae DS. Age at onset of selected mental disorders in five community populations. Arch Gen Psychiatry 1990;47:511-518.

2. Kessler RC, Amminger GP, Aguilar-Gaxiola S, Alonso J, Lee S, Ustun TB. Age of onset of mental disorders: a review of recent literature. Curr Opin Psychiatry 2007;20:359-364.

3. Costello EJ, Egger H, Angold A. 10-year research update review: the epidemiology of child and adolescent psychiatric disorders: I. Methods and public health burden. J Am Acad Child Adolesc Psychiatry 2005; 44:972-986.

4. Patel V, Flisher AJ, Hetrick S, McGorry P. Mental health of young people: a global public-health challenge. Lancet 2007;369:1302-1313.

5. Rutter M, Sroufe LA. Developmental psychopathology: concepts and challenges. Dev Psychopathol 2000;12:265-296.

6. Cohen P, Cohen J, Kasen S, Velez CN, Hartmark C, Johnson J, et al. An epidemiological study of disorders in late childhood and adolescence--I. Age- and gender-specific prevalence. J Child Psychol Psychiatry 1993; 34:851-867.

7. Oh KJ. Manual for the ASEBA School-Age forms. Seoul: HUNO; 2010.

8. Kim YS, Cheon KA, Kim BN, Chang SA, Yoo HJ, Kim JW, et al. The reliability and validity of Kiddie-Schedule for Affective Disorders and Schizophrenia-Present and Lifetime Version- Korean version (K-SADSPL-K). Yonsei Med J 2004;45:81-89.

9. Costello EJ, Mustillo S, Erkanli A, Keeler G, Angold A. Prevalence and development of psychiatric disorders in childhood and adolescence. Arch Gen Psychiatry 2003;60:837-844.

10. Yang SJ, Cheong S, Hong SD. Prevalence and correlates of attention deficit hyperactivity disorder: school-based mental health services in Seoul. J Korean Neuropsychiatr Assoc 2006;45:69-76.

11. Biederman J, Mick E, Faraone SV, Braaten E, Doyle A, Spencer T, et al. Influence of gender on attention deficit hyperactivity disorder in children referred to a psychiatric clinic. Am J Psychiatry 2002;159:36-42.

12. Faraone SV, Biederman J, Mick E. The age-dependent decline of attention deficit hyperactivity disorder: a meta-analysis of follow-up studies. Psychol Med 2006;36:159-165.

13. Hill JC, Schoener EP. Age-dependent decline of attention deficit hyperactivity disorder. Am J Psychiatry 1996;153:1143-1146.

14. Murray J, Anselmi L, Gallo EA, Fleitlich-Bilyk B, Bordin IA. Epidemiology of childhood conduct problems in Brazil: systematic review and meta-analysis. Soc Psychiatry Psychiatr Epidemiol 2013;48:1527-1538.

15. Lahey BB, Schwab-Stone M, Goodman SH, Waldman ID, Canino G, Rathouz PJ, et al. Age and gender differences in oppositional behavior and conduct problems: a cross-sectional household study of middle childhood and adolescence. J Abnorm Psychol 2000;109:488-503.

16. Zoccolillo M. Gender and the development of conduct disorder. Dev
Psychopathol 1993;5:65-78.

17. Wade TJ, Cairney J, Pevalin DJ. Emergence of gender differences in depression during adolescence: national panel results from three countries. J Am Acad Child Adolesc Psychiatry 2002;41:190-198.

18. Cyranowski JM, Frank E, Young E, Shear MK. Adolescent onset of the gender difference in lifetime rates of major depression: a theoretical model. Arch Gen Psychiatry 2000;57:21-27.

19. Thapar A, Collishaw S, Pine DS, Thapar AK. Depression in adolescence. Lancet 2012;379:1056-1067.

20. Hankin BL, Abramson LY. Development of gender differences in depression: description and possible explanations. Ann Med 1999;31:372379.

21. Goodwin GM, Anderson I, Arango C, Bowden CL, Henry C, Mitchell $\mathrm{PB}$, et al. ECNP consensus meeting. Bipolar depression. Nice, March 2007. Eur Neuropsychopharmacol 2008;18:535-549.

22. Masi G, Mucci M, Favilla L, Romano R, Poli P. Symptomatology and comorbidity of generalized anxiety disorder in children and adolescents. Compr Psychiatry 1999;40:210-215.

23. Treadwell KRH, Flannery-Schroeder EC, Kendall PC. Ethnicity and gender in relation to adaptive functioning, diagnostic status, and treatment outcome in children from an anxiety clinic. J Anxiety Disord 1995; 9:373-384.

24. Vicente B, Kohn R, Rioseco P, Saldivia S, Levav I, Torres S. Lifetime and 12-month prevalence of DSM-III-R disorders in the Chile psychiatric prevalence study. Am J Psychiatry 2006;163:1362-1370.

25. Kessler RC, Berglund P, Demler O, Jin R, Merikangas KR, Walters EE. Lifetime prevalence and age-of-onset distributions of DSM-IV disorders in the National Comorbidity Survey Replication. Arch Gen Psychiatry 2005;62:593-602.

26. Canino G, Shrout PE, Rubio-Stipec M, Bird HR, Bravo M, Ramirez R, et al. The DSM-IV rates of child and adolescent disorders in Puerto Rico: prevalence, correlates, service use, and the effects of impairment. Arch Gen Psychiatry 2004;61:85-93.

27. Esbjorn BH, Hoeyer M, Dyrborg J, Leth I, Kendall PC. Prevalence and co-morbidity among anxiety disorders in a national cohort of psychiatrically referred children and adolescents. J Anxiety Disord 2010;24: 866-872.

28. Costello EJ, Egger HL, Angold A. The developmental epidemiology of anxiety disorders: phenomenology, prevalence, and comorbidity. Child Adolesc Psychiatr Clin N Am 2005;14:631-648.

29. Beesdo K, Knappe S, Pine DS. Anxiety and anxiety disorders in children and adolescents: developmental issues and implications for DSM-V. Psychiatr Clin North Am 2009;32:483-524.

30. Biederman J, Ball SW, Monuteaux MC, Kaiser R, Faraone SV. CBCL clinical scales discriminate ADHD youth with structured-interview derived diagnosis of oppositional defiant disorder (ODD). J Atten Disord 2008;12:76-82.

31. Eimecke SD, Remschmidt H, Mattejat F. Utility of the Child Behavior Checklist in screening depressive disorders within clinical samples. J Affect Disord 2011;129:191-197.

32. Ferdinand RF. Validity of the CBCL/YSR DSM-IV scales Anxiety Problems and Affective Problems. J Anxiety Disord 2008;22:126-134. 